ISSN 0717 - 2877

Universidad de Talca - Facultad de Ciencias Jurídicas y Sociales

Una propuesta sobre la dimensión religiosa de los ciudadanos en una nueva Constitución

Diego Andrés Molina Conzué

Trabajo recibido el 28 de marzo de 2018 y aprobado el 5 de agosto de 2019

\title{
Una propuesta sobre la dimensión religiosa de los ciudadanos en una nueva Constitución*
}

\author{
A PROPOSAL ON THE RELIGIOUS DIMENSION OF CITIZENS IN A NEW CONSTITUTION
}

DiEGo ANDRÉS MOLINA CONZUÉ**

RESUMEN

El Estado debe preocuparse, no solo de la dimensión terrenal de la vida humana, sino que también de la religiosa, pero entendida como hecho social. La actitud del Estado se traducirá en el llamado Derecho Eclesiástico del Estado, especial rama del derecho que tiene cuatro principios principales: libertad religiosa, laicidad, cooperación e igualdad ante la ley y no discriminación. Con todo, para una adecuada protección del hecho religioso, las respectivas disposiciones de la nueva Constitución deben basarse en los ya enunciados principios.

\section{ABSTRACT}

The State must worry not only of the earthly dimension of human life, but also religious, but as a social fact. The attitude of the state will result in the call Ecclesiastical Law, special branch of law that has four main principles: religious freedom, secularism, cooperation and equality before the law and non-discrimination. However, for adequate protection of religion, the respective provisions of the new Constitution must be based on the already mentioned principles.

PALABRAS CLAVE

Nueva Constitución, libertad religiosa, Derecho Eclesiástico del Estado.

KEY WORDS

New Constitution, religious freedom, the State Ecclesiastical Law.

\section{Proemio}

En el siguiente artículo deseamos abordar, desde una perspectiva jurídica, un aspecto de la vida humana, social y jurídica.

El análisis que realizaremos busca formular una propuesta normativa para la nueva Carta Fundamental. Para tal finalidad, en primer lugar, nos referiremos al concepto de Derecho Eclesiástico del Estado. Luego, analizaremos el tratamiento que realiza actualmente nuestra Constitución sobre esta rama del derecho, tanto de las normas que directa e indirectamente integran la disciplina. Por último, desarrollaremos los principios que, en abstracto y en el sistema chileno, deben inspirar la nueva normativa constitucional. Con todo, no nos referiremos al tópico de los concordatos.

\footnotetext{
* Agradecemos enormemente las revisiones y comentarios del profesor Dr. Carlos Salinas Araneda. De igual modo a la licenciada Elizabeth Torres y los ayudantes, Claudio Escobar y Pablo Aldunate.

** Abogado, Licenciado en Ciencias Jurídicas por la Pontificia Universidad Católica de Valparaíso. Diplomado en Derecho Administrativo y Administrativo Sancionador por la misma casa de estudios. Cuenta con curso de especialización en Derecho Migratorio por la Pontificia Universidad Católica de Chile. Coordinador académico, Diplomado en Contratación Pública, Derecho PUCV. Profesor curso la Normas y el Género, Derecho PUCV, Valparaíso, Chile. Profesor ayudante de Derecho Internacional Público en la Universidad Andrés Bello, Chile. Correo electrónico: diego.molina@pucv.cl.
} 


\section{La dimensión religiosa de los ciudadanos en la Constitución}

Es indudable afirmar que el fenómeno religioso (léase la religión), esto es, "la relación vital del hombre con Dios" ${ }^{1}$, es un elemento inherente a su dignidad, toda vez que constituye un elemento propio de la realidad humana. Frente a la afirmación anterior, el Estado, como creación jurídica humana destinada a su servicio, está llamado a adoptar una actitud frente al fenómeno religioso, no por su carácter religioso propiamente tal (elemento que le otorga una especialidad en relación con otros hechos de la sociedad ${ }^{2}$ ), sino en cuanto hecho social ${ }^{3}$.

En consecuencia el Estado debe adoptar una actitud jurídica frente al fenómeno religioso. Dicha actitud, teniendo por objeto de regulación estatal el fenómeno religioso como hecho social, contendrá valores y principios inspiradores propios y distintivos dentro del derecho público.

Esta especial área del derecho público es el Derecho Eclesiástico del Estado: el derecho del Estado que se refiere al fenómeno religioso como realidad social Sobre el particular, Salinas Araneda señala que

en [...] ocasiones es el Estado mismo que dicta normas para regular el factor religioso en su dimensión social; el conjunto de normas de origen estatal dirigidas a regular en su dimensión de justicia esta natural tendencia del hombre a lo sobrenatural cuando ella se convierte en un factor social es el Derecho Eclesiástico del Estado, moderna rama del derecho occidental que pretende construir sistemáticamente, conforme a unos principios informadores particulares, una rama autónoma del derecho con consistencia científica propia ${ }^{4}$.

Por su parte, Del Picó Rubio nos señala que

en cuanto al Derecho Eclesiástico del Estado, su carácter disciplinario lo ubica dentro del Derecho público, en tanto marco jurídico que regula la creación de las entidades en base al reconocimiento de preexistencia que efectúa el Estado, pero las normas de producción interna, denominadas en Derecho comparado como normas de derecho eclesiástico particular, no tienen este carácter, discutiéndose doctrinariamente su naturaleza jurídica, toda vez que se proyectan incluso al ámbito civil en lo que a regulación de la personalidad jurídica se refiere ${ }^{5}$.

Consecuencialmente, una nueva Constitución de la República de Chile, al constituir un texto en que la nación expresa solemnemente su voluntad sobre los marcos que precisan en documento escrito en que se determina, entre otros elementos, las libertades ciudadanas ${ }^{6}$, para ser respetuosa de la dignidad humana debe consagrar adecuadamente el derecho fundamental a la libertad religiosa, como de los principios inspiradores del Derecho Eclesiástico del Estado vigente.

\section{Situación actual del Derecho Eclesiástico del Estado en la Constitución}

La Constitución de 1980 presenta a lo largo de su articulado pocas disposiciones que se refieren a la dimensión religiosa de los ciudadanos.

\footnotetext{
${ }^{1}$ SALINAS (2004), p. 93.

${ }^{2}$ SALDAÑA (1999), p. 79.

${ }^{3}$ Véase SALINAS (2004), p. 215.

${ }^{4}$ SALINAS (2009), p. 501.

${ }^{5}$ DEL PICÓ (2013b), pp. 7-8.

${ }^{6}$ SILVA (1997a), p. 85.
} 
Con todo, podemos clasificar estas disposiciones en dos grupos, atendiendo a la relación que guardan con el fenómeno religioso: 1) aquellas que se refieren propiamente a materias eclesiasticistas y 2) aquellas que sin referirse a materias eclesiasticistas dicen relación con ellas. Además, hay un tercer grupo las normas provenientes desde el derecho internacional. A continuación, nos referiremos solo a las dos primeras categorías.

\subsection{Normas que se refieren propiamente a materias eclesiasticistas}

La primera de las normas que se refiere al factor religioso es el Art. 1 inc. 4 de la Constitución, ubicada en el Capítulo I: Bases de la Institucionalidad. Resaltamos la ubicación de la norma en comento, puesto que el Capítulo I consagra una serie de principios y valores que sirven como criterios interpretativos y orientadores de todo el ordenamiento jurídico ${ }^{7}$.

El Art. 1 inc. 4 se refiere al factor religioso al señalar que es deber del Estado

contribuir a crear las condiciones sociales que permitan a todos y a cada uno de los integrantes de la comunidad nacional su mayor realización espiritual y material posible, con pleno respeto a los derechos y garantías que esta Constitución establece.

En esta norma existe una referencia directa al fenómeno religioso, pues el constituyente reconoce que la realidad humana no es solo material, sino que también presenta una realidad inmaterial y trascendente ${ }^{8}$.

La referida disposición prescribe que el Estado, siendo respetuoso del principio de primacía de la persona humana, y del principio de servicialidad, debe adoptar las medidas para que los seres humanos alcancen, en su vida, su mayor realización espiritual, esto es, que puedan alcanzar sus proyecciones y deseos de naturaleza trascendente no material, contribuyendo, de esta forma, a alcanzar el bien común.

La segunda norma es el Art. $19 \mathrm{~N}^{\circ} 6$. En ello se ha entendido que el constituyente ha consagrado a libertad religiosa.

El Art. $19 \mathrm{~N}^{\circ} 6$ prescribe:

La Constitución asegura a todas las personas:

La libertad de conciencia, la manifestación de todas las creencias y el ejercicio libre de todos los cultos que no se opongan a la moral, a las buenas costumbres o al orden público.

Las confesiones religiosas podrán erigir y conservar templos y sus dependencias bajo las condiciones de seguridad e higiene fijadas por las leyes y ordenanzas.

Las iglesias, las confesiones e instituciones religiosas de cualquier culto tendrán los derechos que otorgan y reconocen, con respecto a los bienes, las leyes actualmente en vigor. Los templos y sus dependencias, destinados exclusivamente al servicio de un culto, estarán exentos de toda clase de contribuciones.

\footnotetext{
7 Véase VALENZUELA (2006), pp. 18-19 y SILVA (1997b), pp. 18-19.

${ }^{8}$ Pese a que no se agota en lo religioso, sino que incorpora también otras dimisiones.
} 
Cabe hacer presente que la norma referida tiene su origen en la Constitución de 1925, específicamente el Art. $10^{9}$. Dicha disposición, sin mayores alteraciones ${ }^{10}$, se mantuvo en la actual Constitución de 1980.

Un análisis de la norma hace notar, en primer lugar, que la Constitución no consagra expresamente la libertad religiosa, a diferencia de los instrumentos internacionales sobre derechos humanos, v. gr. el Pacto Internacional de Derechos Civiles y Políticos (Art. 18) ) $^{11}$ y la Convención Americana de Derechos Humanos (Art. 12) ${ }^{12}$.

En efecto, la Constitución garantiza la libertad de conciencia, entendiendo por tal "el resultado de un proceso de aprendizaje moral formal e informal que permite al individuo formular, en su fuero interno, el juicio de deber que ilumina algunos de sus actos" ${ }^{13}$. En específico, "el derecho que garantiza la libertad de conciencia hace referencia al juicio moral sobre las propias acciones y a la actuación en conformidad con dicho juicio moral" ${ }^{14}$, y no expresamente la libertad religiosa ${ }^{15}$.

Por otro lado, la Constitución asegura el derecho de manifestar todas las creencias. La Constitución hace referencia a la fe y a la religión con ocasión de dicho derecho. En efecto, aunque esta no reconoce la libertad religiosa de manera directa, lo hace por medio de sus manifestaciones concretas $^{16}$. Por ello se ha entendido que "si la creencia se aproxima a la fe, su aplicación se circunscribe a la religión, extendiendo la cobertura de la Constitución a sus manifestaciones externas que no constituyen ejercicio del culto"17, debido a que este último aspecto está cubierto por el derecho específico de ejercicio libre de todos los cultos. Así, "en la práctica, la libertad religiosa o, si se prefiere, la manifestación de las creencias y el ejercicio libre del culto, se materializa en un conjunto de derechos explicitados y no explicitados por el ordenamiento jurídico" ${ }^{18}$.

\footnotetext{
9 "Las iglesias, las confesiones e instituciones religiosas de cualquier culto, tendrán los derechos que otorgan y reconocen, con respecto a los bienes, las leyes actualmente en vigor; pero quedarán sometidas, dentro de las garantías de esta Constitución, al derecho común para el ejercicio del dominio de sus bienes futuros. Los templos y sus dependencias, destinados al servicio de un culto, estarán exentos de contribuciones".

${ }^{10}$ Véase PIMSTEIN (2005), pp. 85-87.

11 "1. Toda persona tiene derecho a la libertad de pensamiento, de conciencia y de religión; este derecho incluye la libertad de tener o de adoptar la religión o las creencias de su elección, así como la libertad de manifestar su religión o sus creencias, ind ividual o colectivamente, tanto en público como en privado, mediante el culto, la celebración de los ritos, las prácticas y la enseñanza.

2. Nadie será objeto de medidas coercitivas que puedan menoscabar su libertad de tener o de adoptar la religión o las creencias de su elección.

3. La libertad de manifestar la propia religión o las propias creencias estará sujeta únicamente a las limitaciones prescritas por la ley que sean necesarias para proteger la seguridad, el orden, la salud o la moral públicos, o los derechos y libertades fundamentales de los demás. 4. Los Estados Partes en el presente Pacto se comprometen a respetar la libertad de los padres y, en su caso, de los tutores legales, para garantizar que los hijos reciban la educación religiosa y moral que esté de acuerdo con sus propias convicciones".

12 "Libertad de conciencia y de religión.

1. Toda persona tiene derecho a la libertad de conciencia y de religión. Este derecho implica la libertad de conservar su religión o sus creencias, o de cambiar de religión o de creencias, así como la libertad de profesar y divulgar su religión o sus creencias, individual o colectivamente, tanto en público como en privado.

2. Nadie puede ser objeto de medidas restrictivas que puedan menoscabar la libertad de conservar su religión o sus creencias o de cambiar de religión o de creencias.

3. La libertad de manifestar la propia religión y las propias creencias está sujeta únicamente a las limitaciones prescritas por la ley y que sean necesarias para proteger la seguridad, el orden, la salud o la moral públicos o los derechos o libertades de los demás.

4. Los padres, y en su caso los tutores, tienen derecho a que sus hijos o pupilos reciban la educación religiosa y moral que esté de acuerdo con sus propias convicciones".

${ }^{13}$ BRONFMAN et al. (2012), p. 176.

${ }^{14}$ SALINAS (2004), p. 93.

${ }^{15}$ En contra de dicha postura encontramos autores como Cea Egaña, para quien "ciertamente, las creencias son secuela de vida en las gracias divina, cuyo germen está en la libertad de conciencia ligada con la religión. La manifestación posterior de tales creencias coincide, por lo mismo, con la exteriorización de la libertad de conciencia”. CEA (2012), p. 231.

${ }^{16}$ BRONFMAN et al. (2012), p. 183.

${ }^{17}$ BRONFMAN et al. (2012), p. 181.

${ }^{18}$ BRONFMAN et al. (2012), p. 184. Para Salinas Araneda solo se manifiesta expresamente en el ejercicio libre de todos los cultos. SALINAS (2004), p. 98.
} 
Por su parte, Silva Bascuñán distingue en la libertad religiosa un fuero interno de uno externo. El fuero interno se encuentra recogido en la libertad de conciencia, pues "el hombre tiene derecho a pensar y a adherir a la verdad de cualquier orden que le presente su inteligencia, y de hacerlo espontáneamente sin presiones de ninguna especie"19; mientras que el fuero externo se contiene en el derecho a manifestar todas las creencias (ya que a través de ella se profesa la verdad en materia religiosa ${ }^{20}$ ) y el ejercicio libre de todos los cultos (este "último no está vinculado al contenido de la fe religiosa, sino a una especial actividad: la manifestación religiosa a través del culto"21).

Nosotros consideramos que la libertad religiosa es aquel derecho humano por el cual una persona, individual o colectivamente, opta y manifiesta una relación con lo religioso en un plano de libertad e independencia ${ }^{22}$. Es un derecho genérico, marcadamente definido por la autonomía en que se elige y vive el fenómeno religioso. En tal orden nos apoyamos en el planteamiento de Salinas Araneda, para quien

la creencia en Dios - cualquiera sea el nombre que le demos - puede implicar una posición de la persona sobre la verdad, el bien y la belleza a partir de la fe religiosa que profesa; pero también se puede tener una actitud ante la verdad, el bien y la belleza adoptada al margen o con independencia de una fe religiosa. El tema de Dios es el objeto del derecho de libertad religiosa en el sentido de acto de fe y de profesión de la religión a través de todas sus manifestaciones. Mientras el tema de la actitud de la persona ante la verdad, el bien y la belleza, se derive o no de una postura religiosa, posee autonomía propia y es objeto de la libertad de pensamiento y de la libertad de conciencia ${ }^{23}$.

La autonomía es dada por la tipología en la que se enmarca el derecho a partir de su tipicidad iusfundamental: una libertad. Como señala Aldunate Lizana, las libertades son

derechos fundamentales cuya tipicidad corresponde a ámbitos o atributos de la persona protegidos de la intervención estatal, o en los cuales se encuentra muy limitada ${ }^{24}$, así como las disposiciones relativas a la juridicidad de dicho actuar. Si bien no constituyen exclusivamente 'derechos de defensa', se satisfacen, en un primer momento en la abstención estatal: basta con que el Estado no actue para que se entiendan respetada ${ }^{25}$.

\footnotetext{
${ }^{19}$ SILVA (2006), p. 234.

${ }^{20}$ SILVA (2006), p. 240.

${ }^{21}$ SILVA (2006), p. 242.

${ }^{22}$ Para Salinas Araneda "lo protegido por la libertad religiosa no es sólo el acto positivo de adhesión, sino que la libertad religiosa significa que el hombre debe estar inmune de coacción tanto para realizar el acto de adhesión a Dios y vivir en consecuencia, como para no realizarlo". SALINAS (2004), p. 94. Para Del Picó Rubio la libertad religiosa "es el derecho del hombre a relacionarse con Dios de acuerdo a los dictados de su conciencia, sin coacción de autoridad u otra persona y con la única restricción de respeto al orden público". DEL PICÓ (2010), p. 9. Por su parte, para Celis Brunet y Domínguez Hidalgo "la libertad de conciencia y de religión, es el derecho humano fundado en la dignidad de la persona, que comprende el creer y no creer, la posibilidad de cambiar de creencias o convicciones, y el derecho a manifestarse individual o asociadamente, en público y en privado. Este derecho ha sido reconocido tanto en ámbito internacional como constitucional". CELIS Y DOMÍNGUEZ (2006), p. 98. Finalmente, y para no pecar por exceso, Huaco Palomino, sobre la jurisprudencia de la Corte Interamericana de Derechos Humanos sobre la materia, de forma especial en el caso "La última tentación de Cristo", entiende que "la libertad de religión es la libertad de profesar o no una religión, entendida ésta como la relación del hombre con lo divino (no necesariamente con un dios personal, sino con lo divino que es una relación con la trascendencia) de la cual se desprenden determinadas convicciones éticas, opiniones, creencias y observancias religiosas las cuales se exteriorizan positivamente a través de la libre manifestación individual o colectiva, pública o privada, a través de diversas concreciones particulares. El bien protegido de dicha libertad no es precisamente la religión sino la libertad humana ejercida en sentido religioso, la cual merece protección y promoción para su pleno goce y ejercicio". HUACO (2013), p. 295.

${ }^{23}$ SALINAS (2008), p. 190.

${ }^{24}$ Como lo sería la manifestación de todas las creencias y el ejercicio libre de todos los cultos, al no poder oponerse a la moral, las buenas costumbres y el orden público.

${ }^{25}$ ALDUNATE (2008), p. 143
} 
Consideramos que la actual Constitución no consagra la libertad religiosa en toda su dimensión de forma explícita, empero si la consagra de forma implícita. En efecto, la actual Carta Fundamental se refiere explícitamente a ella solo en lo tocante a "la manifestación de todas las creencias y el ejercicio libre de todos los cultos que no se opongan a la moral, las buenas costumbres y el orden público".

En este orden de ideas, nos parece relevante ahondar en las dimensiones de la libertad religiosa, la que puede clasificarse, conforme al plano en que se desarrolla o bien, conforme a quien es el sujeto que la ejerce ${ }^{26}$.

a) Conforme al plano en que se ejerce, encontramos un plano interno (manifestación intrapersonal) y un plano público (manifestación externa o interpersonal):

- El plano interno es un plano perteneciente al fuero íntimo de la persona. "Hay un aspecto interno, relativo a la formación, mantenimiento y cambio de las propias convicciones religiosas. Este aspecto, por referirse al fuero íntimo del individuo, resulta inmune a toda coacción estatal" ${ }^{27}$. Es decir, realizará una actividad de discernimiento y juicio para, fruto de esto, asumir o rechazar una determinada religión o creencia religiosa. En dicha línea, para Nogueira Alcalá

en la vertiente interna, la libertad religiosa garantiza la existencia de una esfera de libertad, un espacio de autodeterminación intelectual del fenómeno religioso, consistente en creer, cambiar o abandonar creencias religiosas, [...] así la libertad religiosa asegura la libertad de creyentes, agnósticos y ateos por igual ${ }^{28}$.

Este plano no está expresamente protegido por la Constitución, empero, al constituir un plano que se desarrolla sólo en la psiquis del sujeto, es indiferente que el derecho, como ordenación ética de naturaleza externa, lo consagre. No obstante, ello no quiere significar que no pueda adoptar las medidas necesarias para evitar que factores externos condicionen la libre elección del sujeto ${ }^{29}$. El plano interno también protege la forma de vivir personalmente la fe optada. Pese a la falta de reconocimiento expreso de esta faz, toda vez que la Constitución solo reconoce manifestaciones externas de la libertad religiosa, supone la existencia su un cariz interno de este, debido a que su existencia es requisito para que pueda hablarse de una dimensión externa.

- El plano público, por su parte, es el plano externo o interpersonal de la libertad religiosa, y guarda relación a la forma en que se vive la opción religiosa en sociedad, y que, por tanto, se haya limitada por ciertos parámetros ${ }^{30}$, como ya señalaremos. Dentro de sus

\footnotetext{
${ }^{26}$ Estas diversas manifestaciones de la libertad religiosa se hayan recogidas en Ley $\mathrm{N}^{\circ} 19.638$, de 1999, art. 6.

${ }^{27}$ ARLETTAZ (2012), p. 348.

${ }^{28}$ NOGUEIRA (2006), p. 23.

29 "Aunque generalmente se considera que los movimientos teológicos y éticos del fórum interno no son susceptibles de afectación externa, pensamos que en casos extremos ello podría suceder cuando por ejemplo, se pretende afectar la psiquis humana con la finalidad de inducirla a determinado pensamiento o creencia religiosa, o bien cuando siendo inexistente la práctica religiosa (por temor fundado a ser eliminados), las personas son acosadas y perseguidas meramente por el hecho de saberse que detentan una creencia religiosa determinada. En estos casos, no se trata de una represión a la exteriorización de la creencia sino algo más grave: de una inducción no solicitada a tener determinadas creencias". HUACO (2013), p. 310.

${ }^{30}$ Nuestro texto constitucional fija los límites del derecho en comento en la moral (aquella ordenación ética que se da la razón por la cual se puede distinguir lo correcto de lo incorrecto, y lo bueno de lo malo, y que varía de acuerdo a las circunstancias históric as culturales de una comunidad humana), las buenas costumbres (aquel conjunto de pautas éticas de carácter social no coactivas que se da un cuerpo humano para las relaciones entre sus miembros, y que varía de acuerdo a las circunstancias históricas culturales de una comunidad
} 
manifestaciones encontramos la expresión de la opción religiosa en sociedad, que se haya protegida por el derecho a "la manifestación de todas las creencias" y, además, encontramos una protección a una específica forma de ejercicio: "el ejercicio libre de todos los cultos". Pese a todo, la Constitución no se refiere a otras manifestaciones, como el derecho a obtener asistencia religiosa en el lugar en que se encuentre. ${ }^{31}$ Empero, no constituyen manifestaciones de la libertad religiosa aquellas conductas realizadas por un motivo religioso, es decir, aquellas conductas que, no obstante tener como causa una prescripción religiosa, al no constituir formas de relacionarse con lo divino, no se encuentran comprendidas en ella, v. gr. la fundación de un establecimiento educacional, la formación de un centro asistencial de salud, la fundación de un centro de asistencia social.

b) Atendiendo al sujeto que la ejerce, la libertad religiosa es susceptible de ser observada en una dimensión individual y colectiva.

- La dimensión individual de la libertad religiosa corresponde al ejercicio dicho derecho por parte de una persona natural tanto en su fuero interno como externo, aunque mirada desde su singularidad. Es más, "la libertad religiosa [...] es un derecho eminentemente subjetivo del que son titulares todas las personas naturales en virtud del principio de la supremacía de la dignidad personal"32.

- La dimensión colectiva, en cambio, es la libertad religiosa que le corresponde a aquellas organizaciones constituidas con fines religiosos. En su conformidad se

reconoce a las entidades religiosas su plena autonomía para el desarrollo de sus fines propios, consagrando el ejercicio libre de su propio ministerio, definido acordado por la propia entidad; reconociendo la facultad para las entidades de establecer su propia organización interna y jerarquía; garantizando el derecho a difundir el credo y de manifestar su doctrina, sin otra limitación que el respeto a la moral, a las buenas costumbres y al orden público ${ }^{33}$.

Frente a tal escenario consideramos, como ya lo señalaremos, que en la nueva Constitución sería conveniente que se consagre expresamente el derecho a la libertad religiosa, mediante una norma general en la que puedan entenderse comprendidas las diferentes dimensiones y manifestaciones de la libertad religiosa, así como su dimensión individual y colectiva, sin perjuicio a que a vía ejemplar se nombren ciertos derechos específicos, o se encomiende al legislador la función desarrollar las diversas manifestaciones de la libertad religiosa. Creemos que la segunda opción es la más adecuada, toda vez se resulta difícil, atendiendo la relevancia y permeabilidad que tiene en diferentes esferas de la vida de las personas y la sociedad, determinar cuáles manifestaciones de la libertad religiosa en su cariz externo son más relevantes. Del mismo modo, se evita restringir la protección constitucional a determinadas manifestaciones en perjuicio de otras.

humana) y el orden público (conjunto de normas y principios jurídicos de un Estado, positivados o no, independientes de su fuente que deben ser respetados y pueden ser exigidos. Incluye los derechos fundamentales, ya que ellos se hayan recogidos por la Constitución o los Tratados Internacionales ratificados por Chile y vigentes). Sobre el particular véase DEL PICÓ (2013a), pp. 479-486 y SALINAS (2004), pp. 117-124.

${ }^{31}$ No obstante, el Art. 6 de la Ley № 19.638, de 1999, si los recoge. Del mismo modo, véase DEL PICÓ (2013b), pp. 17-21.

32 HUECO (2013), p. 299.

${ }^{33}$ DEL PICÓ (2010), p. 10. 
Finalmente, debemos señalar que es conveniente que se mantengan los límites a las expresiones externas de la libertad religiosa, sector en que el derecho puede actuar en atención a la vida en sociedad Sobre el particular Shambeck señala que

la libertad religiosa se ve acompañada también de límites. La creencia propiamente dicha se protege sin restricción, pero el ejercicio o difusión de la fe puede encontrar freno si afecta a intereses de terceros. Ha de tratarse de limitaciones proporcionadas, apoyadas por una ley y contempladas como necesarias para la seguridad pública, el orden, la salud, la moral o la garantía de derechos o libertades ${ }^{34}$.

De igual forma, dichas limitaciones encuentran sus límites en la reserva legal, la protección al contenido esencial y el principio de proporcionalidad (idoneidad de la medida, necesidad de la medida y proporcionalidad en sentido estricto ${ }^{35}$.

\subsection{Normas que guardan relación con materias eclesiástisistas}

Un segundo grupo de normas son aquellas que, sin referirse expresamente al fenómeno religioso, están en estrecha relación con él puesto que se refiere a la realidad humana, individual o colectivamente considerada, como así también a la libertad religiosa como derecho fundamental.

El primer artículo es el Art. 1 de la Constitución en sus incisos 1, 3 y 5.

El primer inciso hace referencia a la realidad del hombre en su individualidad, reconociendo que todos son iguales en dignidad y derechos. , Por ello, "las características que un su frase inicial y también en el inciso $4^{\circ}$ del mismo Art. $1^{\circ}$ reconoce el constituyente a la persona humana, explican el contenido de otros preceptos sustanciales que son su mera consecuencia" ${ }^{\prime 36}$, como lo es el Art. 19 $\mathrm{N}^{\circ} 6$ de la Constitución. Así, es posible entender que el Estado reconoce que la forma de ver y relacionarse con el fenómeno religioso, toda vez que este constituye parte inherente a la vida humana, correspondiendo un mismo trato a todas las religiones, e incluso grupos ateos, más no por la verdad de sus creencias, sino en cuanto a realidad social.

Posteriormente, el inc. 3 hace referencia a los grupos intermedios. El Estado, señala la Constitución, "reconoce y ampara a los grupos intermedios a través de los cuales se organiza y estructura la sociedad y les garantiza la adecuada autonomía para cumplir sus fines propios". En esta norma el constituyente, propio de una sociedad plural y liberal, reconoce una especial posición a

cualquiera pluralidad de personas que de algún modo se hayan vinculado[s] por [una] determina situación, y así no son ni las personas separadamente consideradas ni en cierto modo tampoco las familias, que tienen una unidad no nacida sustancialmente de la voluntad de su integrantes, ni las simples agrupaciones o aglomerados inorgánicos ${ }^{37}$,

bajo la expresión grupo intermedio.

Las iglesias y confesiones religiosas, sea que cuenten o no con personalidad jurídica, son grupos intermedios $y$, además, titulares del derecho de libertad religiosa por su composición humana. En efecto, en ellas los seres humanos se agrupan en torno a una especial visión y

\footnotetext{
${ }^{34}$ SHAMBECK (2011), p. 162.

${ }^{35}$ Véase ALDUNATE (2008), pp. 256-267.

${ }^{36}$ SILVA (1997b), pp. 32-33.

${ }^{37}$ SILVA (1997b), p. 44.
} 
comprensión del fenómeno religioso. Con todo, entendemos que la Constitución ampara la libertad religiosa en el inc. 3 en su faz colectiva, no en cuanto grupo religioso, sino que como grupo intermedio. En el inc. 5, por su parte, encontramos dos actitudes del Estado que se relacionan con lo religioso. Por un lado, al "promover la integración armónica de todos los sectores de la nación" y, por el otro, "asegurar el derecho de las personas a participar con igualdad de oportunidades en la vida nacional"; da cuenta que el constituyente, en su espíritu democrático (que positivará en el Art. 4) asume como deber adoptar medidas públicas que permitan, en la sede que nos convoca, asegurar y permitir la libertad religiosa, al ser un hecho social que, atendiendo a su trascendencia, permite que los seres humanos, individual o colectivamente, y en igualdad de oportunidades, pueda integrarse, formar parte, y desarrollarse más plenamente en sociedad.

Fuera del Art. 1 encontramos el Art. 4 que señala que "Chile es una república democrática". En tal sentido, la norma constitucional da cuenta, al señalar que Chile es una república, que "es una forma de organización estatal que respeta el principio de igualdad ante la ley, puesto que no existen ni personas ni grupos privilegiados" ${ }^{38}$. Por su parte, al señalar que es democrática, "evidencia que la dignidad común de todos exige un tipo de trato [...] inclusivo y participativo para el logro de todas las esferas que involucran decisiones colectivas" 39 .

Así las cosas, en el Art. 4 encontramos que el Estado, por su propia definición, debe orientar su actuar inspirado en los criterios de igualdad e inclusión que, en lo tocante al factor religioso, tiene vitales repercusiones, en cuanto hecho social. Sobre ello ya nos pronunciaremos.

Cerrando el Capítulo I cabe hacer mención a dos disposiciones: el Art. 5 inc. 2 y el Art. 6.

Ambas normas consagran límites para la actuación del Estado. El Art. 5 inc. 2 fija dichos límites en los derechos esenciales que emanan de la naturaleza humana, y que la Constitución o los tratados internacionales ratificados por Chile y que se encuentran vigente garantizan; dentro de los que se encuentra la libertad religiosa, como señalábamos supra.

Por su parte, el Art. 6, da cuenta del principio de legalidad o, mejor dicho, de juridicidad propia de un Estado de Derecho en su sentido formal. En tal sentido, el Estado se ve refrenado en su actuar por la Constitución y las normas dictadas en su conformidad dentro de la que se encuentran aquellas desarrolladas por el legislador, como es el caso de la Ley $N^{\circ} 9.638$, de 1999, o bien por la Administración. Con todo, el Art. 6 tiene un alcance que no se agota en el Estado como individuo sujeto y limitado por la Constitución y las normas dictadas en su conformidad, y consecuencialmente por la libertad religiosa, al declarar el inc. 2 que "los preceptos de esta Constitución ${ }^{40}$ obligan tanto a los titulares o integrantes de dichos órganos [, los estatales,] como a toda persona, institución o grupo".

Dentro del catálogo específico de derechos fundamentales consagrados en la Constitución, que guardan relación con el fenómeno religioso, encontramos el Art. $19 \mathrm{~N}^{\circ} 2$, igualdad ante la ley, el Art. $19 \mathrm{~N}^{\circ} 10$, derecho a la educación; y el Art. $19 \mathrm{~N}^{\circ} 11$, libertad de enseñanza.

La igualdad ante la ley, garantizada en el Art. $19 \mathrm{~N}^{\circ} 2$, es un derecho objetivo general.

En primer lugar es una igualdad, es decir, que es un derecho que exige un especial trato a su titular respecto de un determinado factor de distribución: la ley ${ }^{41}$. Por ello,

se trata de disposiciones relativas al modo de la actuación estatal a nivel legislativo, administrativo o judicial. Se caracteriza porque el respectivo ámbito protectivo no puede ser determinado a partir del

\footnotetext{
${ }^{38}$ GARCÍA Y CONTRERAS (2014), p. 789.

${ }^{39}$ GARCÍA Y CONTRERAS (2014), p. 275.

${ }^{40}$ Remitiéndose al inc. 1 del Art. 6.

${ }^{41}$ Con todo, más correcto sería que la referencia se haga al derecho en su conjunto.
} 
individuo aislado; sólo resulta posible en su relación con otro sujeto, atendiendo a la actuación del Estado, que puede ser contrastada respecto de uno y otro. Aquí el Estado, en principio, no está obligado ni actuar ni a no actuar; pero de llegar a actuar debe hacerlo de una determinada manera ${ }^{42}$.

Es un derecho objetivo. Esto quiere decir, que protege a aquellas personas que se encuentren en una determinada posición distributiva arbitraria de inequidad. De esta forma, es un derecho que no solo se predica respecto de la persona humana, sino que, al proteger de situaciones de inequidad arbitraria producidas por el tercero adjudicador de dos o más personas, interesa, más que la persona, la situación en que ella se ve envuelta. El remedido impetrado ante el desequilibrio injustamente producido, si bien dirá relación con la situación, en el caso de las personas humanas se fundará en su dignidad y derechos, y, tratándose de los órganos estatales, en el principio de juridicidad.

Es un derecho general, toda vez que su campo de actuación no se haya previamente fijado, pues actuará en todos aquellos casos en que se produzca una desigualdad injustificada.

Este derecho cobra especial relevancia en las normas referentes a la dimensión religiosa de los ciudadanos, al constituir estas la pauta de actuación Estatal en relación con el fenómeno religioso. Sobre este aspecto profundizaremos al referirnos al principio de la igualdad y no discriminación.

Por último, encontramos derechos específicos que forman parte de la libertad religiosa: el derecho a la educación (Art. $19 \mathrm{~N}^{\circ} 10$ ), y la libertad de enseñanza (Art. $19 \mathrm{~N}^{\circ} 11$ ). Sobre ellos no nos referiremos por cuanto, si bien forman parte de las normas referentes a la dimensión religiosa de los ciudadanos a nivel constitucional, no son objeto del presente trabajo; además, ellas constituyen expresiones particulares de la libertad religiosa.

\section{Principios inspiradores para la dimensión religiosa de los ciudadanos en la nueva Constitución}

El programa de gobierno de la ex presidenta Bachelet, entre sus muchas propuestas, postuló la redacción de una nueva Constitución ${ }^{43}$, lo cual se materializó en el Boletín $N^{\circ}$ 11.617-0744. A mayor abundamiento dentro del programa encontramos bajo el título "Derecho a la libertad de conciencia", que se propone "una Constitución laica y pluralista [que] deba [sic] garantizar a todos el derecho a la libertad de conciencia y a la libertad de cultos con igualdad de trato para todas las iglesias" 45 . Por su parte, el programa de gobierno de presidente Sebastián Piñera, año 2018, ha señalado que fortalecerá y protegerá la libertad religiosa y la igualdad de culto, como un principio esencial de la nación chilena ${ }^{46}$.

En tal sentido, un aspecto que deberá ser abordado adecuadamente en la nueva Constitución ${ }^{47}$, es la posición del Estado frente a lo religioso y, consecuencialmente, su actitud.

En las siguientes líneas abordaremos una propuesta de camino para abordar, en la nueva Constitución, algunos aspectos de la dimensión religiosa de los ciudadanos.

Resulta incuestionable que un Estado Democrático y de Derecho, esto es, un Estado en que se reconoce, promueve y asegura el pluralismo, con todas sus consecuencias, como un valor social,

\footnotetext{
${ }^{42}$ ALDUNATE (2008), p. 144.

${ }^{43}$ BACHELET (2013), pp. 30-35.

${ }^{44}$ Ingresó al Senado con fecha 6 de marzo de 2018.

${ }^{45}$ BACHELET (2013), p. 31.

${ }^{46}$ PIÑERA (2017), p. 172.

${ }^{47}$ El mencionado mensaje en su Art. $19 \mathrm{~N}^{\circ}$ 9, salvo por la expresa mención de la objeción de conciencia, no altera la norma constitucional vigente.
} 
y en el cual "las personas e instituciones del Estado ejercen sus potestades sujetos a reglas jurídicas que se aplican igualitariamente, y su poder tiene como límite el pleno respeto a los derechos fundamentales" 48 , la preocupación sobre lo religioso, en cuanto hecho social, reviste de un importancia capital.

El Estado para cumplir tal función debe articular su actuar sobre la base de ciertos principios informadores, "debido a que por su propia naturaleza, expresan valores superiores que, como patrimonio solidario, tiene y quiere el pueblo chileno en materia religiosa, independiente de que la formación jurídica de los mismos se haga en la Constitución o en una norma de rango inferior" 49. Además, ellos "dan cuenta de las opciones ${ }^{50}$ fundamentales que el Estado y la sociedad han asumido en relación con el tratamiento del fenómeno religioso, entendido como la dimensión religiosa de la vida del hombre" 51.

Podemos definir los principios informadores de las normas referentes a la dimensión religiosa de los ciudadanos como aquellos criterios jurídicos fundamentales, expresivos de un valor, consagrados o no en norma positiva, que estructuran, delinean, interpretan y limitan el actuar estatal acerca del fenómeno religioso, entendido como fenómeno social.

Cumplen principalmente una función integradora e interpretativa. Y, en suma, constituyen "una regla de conducta jurídico estatal" 52.

Seguidamente analizaremos los principios de Derecho Eclesiástico del Estado que deben inspirar la nueva Constitución, y han sido considerados por la doctrina como principios básicos de dicha área jurídica ${ }^{53}$, y que evidencian la forma en que un Estado respetuoso de la libertad religiosa, en cuanto derecho fundado en la dignidad misma de la persona ${ }^{54}$, debe actuar.

\subsection{Principio de la libertad religiosa}

Salinas Araneda distingue entre la libertad religiosa como derecho y como principio ${ }^{55}$. Como derecho, la libertad religiosa hace referencia a una idea o definición de persona, y conlleva a un ámbito de abstención y no coacción por el Estado; en cambio, si se aprecia como principio, la libertad religiosa de una idea o definición de Estado ${ }^{56}$. Saldaño Serrano, en la misma línea, nos dice que el principio de la libertad religiosa "sólo define al Estado como tal y no más, sirviendo a la persona y reconociéndole sus derechos" 57 .

\footnotetext{
${ }^{48}$ GARCÍA Y CONTRERAS (2014), p. 425.

${ }^{49}$ SALINAS (2004), p. 201.

${ }^{50}$ Énfasis agregado.

${ }^{51}$ DEL PICÓ (2010), p. 8.

${ }^{52}$ SALDAÑA (1999), p. 81.

${ }^{53}$ Véase SALINAS (2004), pp. 197-227, DEL PICÓ (2010), pp. 7-13 y SALDAÑA (1999), pp. 82-91.

${ }^{54}$ PRECHT (2000), p. 116.

${ }^{55}$ En contra de esta idea esta lo planteado por Aldunate Lizana, para quien "la calificación de los derechos fundamentales como valores, y su conversión, en el plano deóntico, a principios, conlleva unas consecuencias que sólo se hacen evidentes al llegar al mom ento de la aplicación del método de ponderación como vía para la solución de casos concretos en que se presenta colisión de principios (lo que se trata más adelante). Pero es importante destacar un punto: la distinción entre reglas y principios sólo es posible para una teoría que no distingue entre textos normativos y norma como entidad de significado resultante de un proceso de construcción normativa. De este modo, es posible decir de una constitución que en su artículo X expresa "Se garantiza la libertad religiosa", que ella resguarda el principio de la libertad religiosa. Esto no es un predicado respecto de lo que la constitución contiene, normativamente, sino que respecto de cómo se va a leer la constitución: una alternativa sería tratar de desarrollar un proceso interpretativo destinado a justificar ciertas reglas en la fórmula "Se garantiza la libertad religiosa"”. ALDUNATE (2010), p. 91.

${ }^{56}$ SALINAS (2004), p. 204.

${ }^{57}$ SALDAÑA (1999), p. 84.
} 
Al fundarse el derecho a la libertad religiosa en la dignidad misma de la persona humana ${ }^{58}$, el Estado en materia religiosa debe reconocer la libertad religiosa como un derecho humano y fundamental, debiendo adecuar su actuar a esta especial dimensión humana, pues "ella es anterior y superior al Estado, y es el fundamento de su legitimidad ante sus propios ciudadanos como ante la comunidad internacional" 59 .

Por ello, el principio de la libertad religiosa se traduce en la actitud que el Estado deberá adoptar para respetar y resguardar adecuadamente la libertad religiosa y que se materializará, consecuencialmente, en decisiones jurídicas que integrarán su orden público. Con todo, no hay que entender el concepto de orden público en un sentido negativo, pues, como indica Del Picó Rubio,

no debe entenderse el orden público como una barrera de protección del Estado y menos de la Administración, sino como un obstáculo, si se admite la metáfora, para proteger los derechos fundamentales ante la pretensión de avasallarlos en función de intereses particulares contrapuestos al bien común legítimamente tutelado por el Estado ${ }^{60}$.

En suma, el principio de la libertad religiosa exige un reconocimiento y amparo por parte del Estado de la libertad religiosa, como derecho, limitando su actividad frente a él y, al mismo tiempo, actuando frente a los casos en que este se ve ilegítimamente afectado, toda vez que constituye un elemento esencial de la persona humana.

Sobre este punto nos referiremos más adelante, de acuerdo a la relación que se establezca entre el principio de la libertad religiosa y el principio de laicidad, de cuya común conjunción el Estado adoptará una determinada actitud acerca de lo religioso desde su posición laica.

En nuestro derecho, este principio se manifiesta en los Art. 1 inc. 1, 3, 4 y 5; el Art. 5 inc. 2; el Art. 6; y, el Art. $19 \mathrm{Ns}^{\circ}$ 6, 10 y 11 de la Constitución.

Del mismo modo, se encuentra reconocido en la Ley $\mathrm{N}^{\circ} 19.638$, de 1999, a lo largo de cuyo articulado se reconoce la libertad religiosa en sus diversos aspectos, desarrollando en su Art. 6 un conjunto de facultades que, a vía ejemplar, forman parte de ella. Aún más, es dable señalar que "el gran mérito de esta ley es haber incorporado formalmente el concepto de libertad religiosa en nuestro ordenamiento jurídico y, sobre todo, haberlo llevado a principio informador del Derecho Eclesiástico chileno" ${ }^{61}$.

\subsection{Principio de laicidad}

En virtud de este principio el Estado asume una posición de neutralidad frente el fenómeno religioso en cuanto cosmovisión (no como hecho social).

El Estado es absoluta y totalmente incompetente en el ámbito interno o de espiritualidad de lo religioso como tal, pero está capacitado para regularlo en cuanto factor social o hecho religioso en sociedad, a través de lo único que tiene el Estado para tratar cualquier factor social, el Derecho ${ }^{62}$.

Resulta conveniente realizar una precisión previa: la laicidad es un concepto diferenciable del laicismo. El primero es aquella posición asumida por el Estado, propia de un Estado democrático,

\footnotetext{
58 PRECHT (2000), p. 116.

${ }^{59}$ HUACO (2013), p. 299.

${ }^{60}$ DEL PICÓ (2013b), p. 485.

${ }^{61}$ SALINAS (2009), p. 503.

62 DEL PICÓ (2013a), p. 87.
} 
y que actúa como criterio de trato para con el fenómeno religioso. El laicismo, en cambio, "cuyo contenido básico se centra en la imposición de una sociedad sin ninguna religión" ${ }^{63}$,

basándose en una cierta ideología, al considerar como derecho de la persona de carácter exclusivamente privado el derecho de manifestar su religión, sea de manera individual o de carácter colectivo, sin reconocerle como parte de la vida social o pública en general [...] [y] es limitante de la libertad religiosa ${ }^{64}$,

busca la negación de lo religioso como hecho de preocupación estatal.

Como destaca Blanco, la laicidad y el laicismo difieren en cuanto

$1^{\circ}$ ) la laicidad es un concepto pacífico; el laicismo es un concepto beligerante; $2^{\circ}$ ) la laicidad es un principio inspirador del diálogo; el laicismo es un principio acelerador del desencuentro; $3^{\circ}$ ) la laicidad genera pluralismo; el laicismo imposición de una idea; es decir, la laicidad avala múltiples convicciones; el laicismo monopoliza la sociedad sin $\operatorname{Dios}^{65}$.

Así, un Estado que reconoce y ampara la libertad religiosa, debe optar por la laicidad y no por el laicismo.

Que el Estado sea laico supone que asumirá una especial postura frente al fenómeno religioso, independiente de la actitud que, en base a dicha posición, adopte en forma ulterior.

La laicidad no solo da cuenta de la neutralidad del Estado, sino que también, y como señala Precht Pizarro, "es hoy por hoy uno de los pilares del sistema republicano"66, ya que "la laicidad cuyo núcleo central es la separación Estado-iglesias- es parte inherente al concepto de democracias" 67 , toda vez que al conjugarse con la libertad religiosa, el Estado debe procurar que todas las dimensiones de lo religioso, en cuanto factor social, tengan cabida, desarrollo y respecto en la sociedad.

En suma, y en palabras del citado autor:

si se parte de la persona, el Estado asume el fenómeno de la libertad religiosa, de manera que sea posible la formación libre de la conciencia y el libre ejercicio de las opciones y convicciones religiosas de cada cual.

En este sentido el Estado se seculariza, adopta la laicidad como fundamento de su actuación frente a las opciones religiosas, pero no adopta el laicismo, porque no se emplea el aparato estatal para secularizar la sociedad, para erradicar el hecho religioso del seno social o para neutralizar la opción religiosa en el plano colectivo ${ }^{68}$.

En la misma línea, Nogueria Alcalá señala que

en la dimensión objetiva del derecho a la libertad religiosa [se] marca[n] los confines de la neutralidad ${ }^{69}$ del Estado, el cual junto con respetar las diversas expresiones religiosas que forman parte de la sociedad, debe remover los obstáculos que se opongan a ello ${ }^{70}$.

\footnotetext{
${ }^{63}$ BLANCO (2009), p. 201.

${ }^{64}$ SALDAÑA (1999), pp. 86-87.

${ }^{65}$ BLANCO (2009), p. 204.

${ }^{66}$ PRECHT (2015a).

${ }^{67}$ PRECHT (2015b).

68 PRECHT (2000), p. 117.

${ }^{69}$ En el entendido de no asumir cierta religión como oficial, o bien negar su existencia como hecho social.

${ }^{70}$ NOGUEIRA (2006), p. 21.
} 
En nuestro derecho este principio se manifiesta en los Arts. 1 inc. 1, 4, 5; 4; 5 inc.2; 6; y 19 $N^{\circ} 6$ de la Constitución.

\subsection{Conjugación de los principios}

Consideramos que son dos los principios que estructuran el Derecho Eclesiástico del Estado: la libertad religiosa y la laicidad ${ }^{71}$. Ellos son los principios fundamentales y basales de esta rama del derecho.

En efecto, al aceptar que Chile es un Estado democrático y de derecho; el principio de libertad religiosa, especial actitud que tiene el Estado sobre lo religioso - y la consecuente posición (postura que adopta el Estado frente al fenómeno religioso) - la laicidad - principio fundado en la plural composición social (relación con el factor democrático) - configuran la actitud o actividad que adoptará. La libertad religiosa es primaria y la laicidad secundaria ${ }^{72}$.

En otras palabras, partiendo de la base del reconocimiento y amparo de la libertad religiosa, que lleva como consecuencia a que el Estado asuma una postura de neutralidad -laicidad- se estructurará el modelo de Derecho Eclesiástico del Estado.

Partiendo de estos dos pilares encontramos diferentes actitudes del Estado.

La primera de ella es la más básica. El Estado se limitará a adoptar una actitud de indiferencia frente a lo religioso, esto quiere decir, reconocerá la libertad religiosa y la amparará frente a las afectaciones que ella sufra (para de esta manera mantener la paz social), empero, no adoptará una actitud activa, esto es, una labor de promoción y cooperación de lo religioso. Un ejemplo de este modelo es el modelo francés luego de 1905.

El segundo modelo da un paso más. En él el Estado no solo adoptará una actitud pasiva y reactiva, sino que adoptará una actitud positiva, esto es, promoverá la libertad religiosa, garantizándola. Preferimos la expresión garantizará ya que ellas es más amplia que la expresión promover, pues la última se agota en aquellas conductas estatales destinadas a apoyar directamente lo religioso; en cambio, garantizar es más comprensivo, ya que no solo se limita a actuaciones directas, sino que a crear las condiciones, directas e indirectas, para un desarrollo y desenvolvimiento integral de la libertad religiosa, sean estas positivas o negativas; por otro lado, pone en mayor relieve su naturaleza de derecho fundamental. En este modelo se halla inmersa la actual normativa chilena. Además, es un modelo que se haya marcado por el principio de cooperación.

Una manifestación de este principio es que las iglesias gocen de personalidad jurídica de derecho público, en la medida que se hayan constituido conforme a derecho. Lo anterior se ve fundamentado por dos argumentos. Primero, la constitución de iglesias, como manifestación colectiva de la libertad religiosa, supone reconocer que las agrupaciones que se formen en el ejercicio de tal derecho "en atención a la relevancia pública de los fines [...] [de la organización], a la función de interés común que cumple y a la valoración social que les acompaña"73. Segundo, permitirá que dichas organizaciones puedan desarrollar de forma autónoma diversos actos en el orden jurídico, cuya realización le estaría imposibilitada de no gozar con dicha personalidad.

\footnotetext{
${ }^{71}$ Véase SALINAS (2004), pp. 213-214 y SALDAÑA (1999), p. 88.

72 Véase SALINAS (2004), p. 206.

${ }^{73}$ DEL PICÓ (2013a), p. 39.
} 


\subsection{El modelo del Derecho Eclesiástico del Estado chileno: el principio de cooperación}

El Estado de Chile, separado de la Iglesia Católica en $1925^{74}$, ha optado por una especial relación con el fenómeno religioso: el principio de cooperación.

El principio de cooperación es aquel principio de Derecho Eclesiástico del Estado, en cuya virtud existe una colaboración entre lo religioso y lo estatal para procurar el bien común. Como principio, por tanto, requiere que el Estado garantice el fenómeno religioso en la sociedad; mientras más plural sea esta, más fuerte debe ser la cooperación.

Este principio difiere del principio de abstención y no intervención del laicismo indiferente, esto es, la manifestación más básica de la laicidad.

Así las cosas, y sobre la base de la laicidad del Estado, "la libertad religiosa en una época de pluralismo redundaría en beneficio de los individuos y también, [sic] el derecho constitucional no tendría sólo un influjo normativo sino también motivador"75.

La elección de este principio radica en dos factores: 1) la composición social de la comunidad y 2) la realidad histórica de la misma. Por ello, es que en Chile se "avanzó en dirección de un sistema de cooperación, basado en la importancia pública de la religión en la sociedad"76.

El principio de cooperación requiere que el Estado asuma una actitud positiva respecto a la libertad religiosa. Va un paso más allá del mero reconocimiento y amparo, esto es, una actitud pasiva y reactiva. Supone que el Estado adopte las medidas necesarias para que la libertad religiosa pueda ser desarrollada plenamente.

En el derecho chileno este principio ha tenido su manifestación más clara e integra en la llamada Ley de Cultos, Ley $N^{\circ} 19.638$, de 1999, en virtud de la cual se establecen los requisitos y procedimientos que deben seguir las iglesias y Confesiones Religiosas para adquirir personalidad jurídica de Derecho Público. Este principio también se manifiesta en las instancias de diálogo (seminarios, mesas de trabajo), como en actividades de integración ( $v$. gr. capellanías castrenses evangélicas).

En suma, el principio de cooperación significa que el Estado busca insertar e integrar la libertad religiosa como valor social.

Con todo, y si bien las finalidades del Estado y las iglesias y confesiones religiosas tienen una "distinción entre sus finalidades no quiere decir un alejamiento o separación radical entre el Estado y las confesiones religiosas, porque se relacionan al ayudar a unos mismo hombres, creyentes o ciudadanos, en la consecución del bien común"77. Del Picó Rubio sobre este punto sentencia que:

considerando que el Estado y las iglesias cooperan en el logro de objetivos de bien común, la separación de la entidad política y de la entidad religiosa no debe significar ignorancia recíproca ni que no deban entrar en relaciones entre síp ${ }^{78}$.

Finalmente, las iglesias y confesiones religiosas, con ocasión de este principio, deben estar atentas y dispuestas a cooperar con el Estado en el logro del bien común; debiendo, consecuencialmente, poner énfasis en tal aspecto.

Este principio se consagra en el Art. 1 inc. 3; inc. 4; e inc. 5 de la Constitución.

\footnotetext{
${ }^{74}$ Véase a PIMSTEIN (2005), pp. 81-82, en que se refiere a los términos de la separación.

${ }^{75}$ SHAMBECK (2011), p. 166.

${ }^{76}$ DEL PICÓ (2013a), p. 13.

77 SALDAÑA (1999), p. 90.

${ }^{78}$ DEL PICÓ (2010), p. 12.
} 
Salinas Araneda afirma que el hecho de que la Ley $N^{\circ} 19.638$, de 1999, haya consagrado de forma expresa la libertad religiosa

significa que el Estado de Chile se considera incapaz de hacer el acto de fe y, por lo mismo, incapaz de asumir una confesión como religión oficial del Estado. Esto, empero, no significa que haya de marginar lo religioso de la vida pública para encerrarlo en la intimidad de las conciencias, como pretenden algunos, sino que ha de asumirlo como un factor social, es decir, una de aquellas dimensiones que, presentes en nuestra sociedad, hacen que los chilenos podamos crecer como personas, que seamos mejores, como pueden serlo otros factores sociales como el arte, el deporte o la cultura ${ }^{79}$.

\subsection{El principio general: igualdad ante el derecho y la no discriminación}

La igualdad ante el derecho y la no discriminación es un principio general, pues su campo de actuación es amplio. Al igual que la libertad religiosa, es derecho y principio. Así, el Tribunal Constitucional nos dice que "la igualdad ante la ley constituye tanto un derecho como una garantía de seguridad jurídica no sólo respecto de la aplicación de las normas jurídicas en general, sino, también respecto del ejercicio de los derechos fundamentales" 80 .

Cabe agregar que, la igualdad no supone un mismo trato, sino que supone un trato diferenciado y adecuado a partir de criterios objetivos diferenciadores.

En términos simples, cada vez que a una persona se le otorga un trato mejor o peor que a otros que se encuentran en una situación similar, debe existir una razón suficiente para ello. De lo contrario, nos encontramos frente a una discriminación no justificada o arbitraria ${ }^{81}$.

Evans de la Cuadra define discriminación arbitraria como "toda diferenciación o distinción, realizada por el legislador o por cualquier autoridad pública, que aparezca como contraria a la ética elemental o a un proceso normal de análisis intelectual; en otros términos, que no tenga justificación racional o razonable" 82 .

De acuerdo a Saldaña Serrano hay que distinguir entre igualitarismo e igualdad. Por el primer término se exige del Estado un mismo trato para todas las confesiones y grupos religioso; por el segundo término, en cambio, se hace referencia a un trato estatal en que no se realizan distinciones infundadas, lo que conlleva un trato no discriminatorio ${ }^{83}$.

Para Del Picó Rubio, este principio

rige para todos los sujetos, incluso en el orden religioso. Todas las personas pueden practicar la religión que compartan, sus ritos y sus derivaciones en otras dimensiones de la vida de las personas. [...] sin que esta igualdad jurídica formal de parte del Estado determine necesariamente que todas las entidades religiosas tengan ante e igual desarrollo institucional, presencia histórica o relevancia social ${ }^{84}$.

\footnotetext{
${ }^{79}$ SALINAS (2009), pp. 503-504.

${ }^{80}$ Tribunal Constitucional, Rol N 2935 de 2015, de 21 de diciembre de 2015.

${ }^{81}$ DÍAZ (2019), p. 174.

82 EVANS (2004), p. 125.

${ }^{83}$ SALDAÑA (1999), p. 88.

${ }^{84}$ DEL PICÓ (2013a), p. 26
} 
De esta forma, y para el Derecho Eclesiástico del Estado, la igualdad ante la ley, y su otra faz, la no discriminación, exigen una conducta estatal positiva y negativa que no realice distinciones arbitrarias basadas en un aspecto cualitativo, o de fondo, de la cosmovisión planteada por el credo religioso.

Este principio se recoge en el Art. 1 inc. 1; inc. 4; inc. 5; y 19 № 2 de la Constitución.

Del mismo modo, el Art. 2 de la Ley $N^{\circ} 19.638$, de 1999, lo consagra, tanto en cuanto señala que "ninguna persona podrá ser discriminada en virtud de sus creencias religiosas, ni tampoco podrán éstas invocarse como motivo para suprimir, restringir o afectar la igualdad consagrada en la Constitución y en la ley".

Otra mención expresa sobre el particular en el orden jurídico interno se encuentra en el Art. 2 de la Ley $\mathrm{N}^{\circ}$ 20.609, de 2012, conocida como Ley Zamudio, toda vez que uno de los factores previstos para fundar una discriminación arbitraria se cuenta la religión o creencia ${ }^{85}$. De esta forma, en caso de establecerse esta distinción es posible proteger la libertad religiosa mediante la acción especial de no discriminación arbitraria.

\section{Conclusiones y propuesta normativa}

Sobre la base de lo dicho concluimos lo siguiente:

En el derecho chileno existen dos principios base del sistema de normas referentes a la dimensión religiosa de los ciudadanos: el principio de libertad religiosa y el de laicidad del Estado. De su común conjugación surge el modelo de laicidad. En el caso de Chile, este modelo, por la realidad social e histórica, es un modelo de laicidad cooperante de lo religioso, reconoce, garantiza y ampara la libertad religiosa.

A partir de este modelo surge un nuevo principio de Derecho Eclesiástico del Estado: el principio de cooperación. Dicho principio es el principio propio del modelo de Derecho Eclesiástico del Estado chileno.

Así, además, y si bien no es privativo de esta rama del derecho, el principio de igualdad ante del derecho y no discriminación, dos caras de la misma moneda (actitud estatal positiva y negativa), constituye un pilar fundamental, que cobra en esta sede un especial protagonismo. Es un principio general.

Así, la nueva Constitución debe inspirarse en cuatro principios:

a) Libertad religiosa (principio basal primario).

b) Laicidad (principio basal secundario).

c) Cooperación (principio de modelo).

d) Igualdad y no discriminación (principio general).

Consideramos que para construir adecuadamente las normas referentes a la dimensión religiosa de los ciudadanos de Chile en la nueva Constitución deben introducirse dos disposiciones.

En la primera deben consagrarse los principios de libertad religiosa, laicidad y cooperación. Creemos que sería factible que la disposición haga referencia a la laicidad del Estado y, seguidamente, se refiera a la actitud del Estado sobre la libertad religiosa mediante las siguientes

\footnotetext{
85 Más aún, una diferenciación fundada en la religión es catalogable como categoría sospechosa, entendiendo por tal "aquellas características o rasgos personales que, como regla general, no deben utilizarse para establecer diferencias entre individuos, tales como la raza, el sexo y la religión, y que el ordenamiento jurídico ha señalado especialmente como indiciarios de discriminación arbitraria". DÍAZ (2019), p. 197.
} 
expresiones: 1) reconoce (asume la existencia del fenómeno religioso como una realidad preexistente frente a la que no debe intervenir, es la dimensión básica de la laicidad, es la actitud pasiva), 2) garantiza (consagra una actuación más activa respecto al fenómeno religioso, es decir, consagra el principio de cooperación; es la actitud activa), y 3) amparar (el Estado hace frente a las afectaciones ilegitimas que sufra la libertad religiosa; es la actitud protectora).

Con todo, esta norma debe circunscribirse en aquel capítulo que consagre los principios rectores del Estado, de manera que orienta todo el ordenamiento jurídico y actuación estatal.

Sobre la igualdad y no discriminación, consideramos que la nueva Constitución debe mantener la redacción el Art. 1 inc. 1 e inc. 5, como así también el Art. 19 № 2.

En cuanto al derecho de la libertad religiosa, creemos que la Constitución debe consagrar la libertad religiosa en términos expresos. Al mismo tiempo, debe distinguirla de la libertad de pensamiento y conciencia.

Debiese, además, regularse en términos amplios, abarcando tanto su faz privada y pública, como su dimensión individual y colectiva. Con todo, puede propenderse a garantizar de forma expresa aquellas manifestaciones externas de la libertad religiosa que se estimen como más relevante, o bien remitir dicha labor al legislador, a efectos que este pueda desarrollar el particular. Creemos que la segunda opción es la más acertada, pues se evita restringir la protección constitucional de la libertad religiosa en su faz externa a aquellas expresiones constitucionalmente previstas. Además, por la importancia personal y social de la libertad religiosa, resulta difícil discriminar que manifestaciones deben contar con expresa regulación constitucional y cuáles no.

Su faz externa, como sí también la de la manifestación de todas las creencias, debe estar limitada. Estimamos que los actuales límites, la moral, buenas costumbres y orden público deben mantenerse; resguardándose, de este modo, la paz y sana convivencia social.

Por otro lado, estimamos que debe consagrarse a nivel constitucional el derecho de las iglesias y confesiones religiosas a adquirir personalidad jurídica de derecho público, para que las mismas puedan alcanzar de forma más plena sus objetivos.

Finalmente, creemos que el actual inc. 3 debe permanecer inmutable, pues otorga protección constitucional a derecho ya adquiridos como referirse a importantes aspectos externos para materializar la libertad religiosa.

A continuación, y a partir de las conclusiones alcanzadas, realizamos la siguiente propuesta normativa para la nueva Constitución:

Artículo. El Estado de Chile es un estado laico que reconoce, garantiza y ampara la libertad religiosa.

Artículo. La Constitución asegura a todas las personas:

Numeral. La libertad de pensamiento, de conciencia y religiosa.

Ninguna persona podrá ser obligada a adquirir, mantener o renunciar a una creencia religiosa. El legislador garantizara las diversas formas en que se puede ejercer externamente la libertad religiosa, de forma individual o colectiva, desarrollándolas apropiadamente. Con todo, la manifestación de todas las creencias y el ejercicio externo de la libertad religiosa no se puede oponer a la moral, las buenas costumbres y el orden público.

Se asegura especialmente el derecho a constituir iglesias y confesiones religiosas con personalidad jurídica de derecho público de conformidad a las leyes; como así mismo, el derecho a erigir y conservar templos y sus dependencias bajo condiciones de seguridad e higiene fijados por las leyes y ordenanzas. 
Las iglesias, las confesiones e instituciones religiosas de cualquier culto tendrán los derechos que otorgan y reconocen, con respecto a los benes, las leyes actualmente en vigor. Los templos y sus dependencias, destinados exclusivamente al servicio de un culto, estarán exentos de toda clase de contribuciones.

\section{BIBLIOGRAFÍA CITADA}

ALDUNATE LIZANA, EDUARDO (2008): Derechos Fundamentales (Santiago de Chile, Legal Publishing).

(2010): "Aproximación conceptual y crítica al neoconstitucionalismo", en: Revista de Derecho (Valdivia) (vol. 23, N 1), pp. 79-102.

ARLETTAZ, FERNANDO (2012): "Libertad religiosa y objeción de conciencia en el derecho constitucional argentino”, en: Estudios Constitucionales (año 10, № 1), pp. 339-372.

BACHeLeT, MiCHelle (2013): Chile de todos. Programa de Gobierno de Michelle Bachelet 2014-2018. Disponible en: http://www.subdere.gov.cl/sites/default/files/noticias/archivos/programamb_1_0.pdf [visitado el 28 de junio de 2019].

BRONFMAN VARGAS, ALAN; MARTíNEZ ESTAY, JOSÉ IGNACIO Y NÚÑEZ POBLETE, MANUEL (2012): Constitución Política Comentada. Parte dogmática (Santiago de Chile, Legal Publishing).

CEA EGAÑA, JOSÉ LUIS (2012): Derecho Constitucional Chileno, segunda edición (Santiago de Chile, Ediciones UC), tomo II.

Celis brunet, ana maría y domínguez hidalgo, carmen (2006): “Celebración del matrimonio en Latinoamérica, desde la perspectiva de la libertad religiosa", en: A.A.V.V., Investigaciones para que nuestros pueblos tengan vida (Santiago de Chile, Ediciones UC), pp. 95-131.

DEL PICÓ RUBIO, JORGE (2010): "La ley de constitución jurídica de entidades religiosas", en: Del Picó, Jorge, Derecho de la libertad de creencias (Santiago de Chile, Legal Publishing), pp. 7-38.

(2013A): “Libertad religiosa y orden público. La colisión entre la noción de orden público y los fines religiosos en el caso de la objeción de la inscripción en el registro de entidades religiosas a la Iglesia de Unificación", en: Estudios Constitucionales (vol. 11, № 2), pp. 451-494.

Publishing).

(2013B): Régimen legal de las iglesias y otras entidades religiosas (Santiago de Chile, Legal

DíAZ DE VALDÉS JULIÁ, JOSÉ MANUEL (2019): Igualdad constitucional y no discriminación (Valencia, Tirand Lo Blanch).

EVANS DE LA CUADRA, ENRIQUe (2004): Los Derechos Constitucionales' tercera edición (Santiago de Chile, Editorial Jurídica de Chile), tomo II. 
garcía Pino, gonzalo y CONTReras VÁsquez, Pablo (2014): “Diccionario Constitucional Chileno", en: Cuadernos del Tribunal Constitucional (vol. 45).

HUACO PALOMINO, MARCO (2013): “Artículo 12. Libertad de conciencia y de religión", en: Steiner, Chirstian; Uribe, Patricia (editores), Convención Americana sobre Derechos Humanos. Comentario (Santiago de Chile, Konrad Adenauer Stiftung), pp. 289-319.

NOGUEIRA ALCALÁ, HUMBERTO (2006): "La libertad de conciencia, la manifestación de creencias y la libertad de culto en el ordenamiento jurídico chileno", en: Ius et Praxis (año 12, N²), pp. 13-41.

PIMSTEIN SCROGGIE, MARÍA ELENA (2005): "Relaciones Iglesia y Estado. Una perspectiva evolutiva desde el derecho chileno del S. XX", en: Consorcio Latinoamericano de Libertad Religiosa, V Coloquio del Consorcio Latinoamericano de Libertad Religiosa (Ciudad de México), pp. 73-99.

PIÑERA, SEBASTIÁN (2017): Construyamos tiempos mejores para Chile. Programa de Gobierno de Sebastián Piñera 2018-2022. Disponible en: http://www.sebastianpinera.cl/images/programaSP.pdf [visitado el 27 de junio de 2019].

PRECHT PIZARRO, JORGE (2000): "La libertad religiosa", en: Revista de Derecho (Valparaíso) (vol. 21), pp. 109-120.

(2015A): Libertad religiosa y ley de cultos. Primera parte. Disponible en: http://www.diarioconstitucional.cl/articulos/libertad-religiosa-y-ley-de-cultos-primera-parte/ [visitado el 17 de marzo de 2017].

(2015B): Libertad religiosa y ley de cultos. Segunda parte. Disponible en: http://www.diarioconstitucional.cl/articulos/libertad-religiosa-y-ley-de-cultos-segunda-parte/ [visitado el 17 de marzo de 2017].

Saldaña SerRano, JAVIer (1999): "Principios del derecho y libertad religiosa", en: Revista de Derecho (Concepción) (vol. 205), pp. 75-91.

SALINAS ARANEDA, CARLOS (2004): Lecciones de Derecho Eclesiástico del Estado de Chile (Valparaíso, Ediciones Universitarias de Valparaíso).

1), pp. 183-202.

(2008): "Estado no confesional y laicismo", en: Revista de Derecho (Coquimbo) (año 15, N

(2009): "El Derecho Eclesiástico del Estado de Chile al tiempo del bicentenario", en: Revista de Derecho (Valparaíso) (vol. 33, № 2), pp. 499-533.

SHAMBECK, HERBERT (2011): "La libertad religiosa y el pluralismo de nuestro tiempo", en: Persona y Derecho (vol. 65, N²), pp. 159-167.

SILVA BASCUÑÁN, ALEJANDRO (1997A): Tratado de Derecho Constitucional (Santiago de Chile, Editorial Jurídica de Chile), tomo I. 
tomo IV.

(1997B): Tratado de Derecho Constitucional (Santiago de Chile, Editorial Jurídica de Chile), (2006): Tratado de Derecho Constitucional (Santiago de Chile, Editorial Jurídica de Chile), tomo XI.

VAlenZUela somarRIVA, eUgenio (2006): Criterios de Hermenéutica Constitucional aplicados por el Tribunal Constitucional. Contribución del Tribunal Constitucional a la Institucionalización Democrática (Santiago de Chile, LOM).

\section{JURISPRUDENCIA CITADA}

REQUERIMIENTO DE INCONSTITUCIONALIDAD PRESENTADO POR UN GRUPO DE DIPUTADOS, respecto de parte de las glosas que indican correspondientes al proyecto de ley de Presupuestos del Sector Público, para el año 2016, correspondiente al Boletín N 10.300-2015 (2015): Tribunal Constitucional 21 de diciembre de 2015, Rol N² 2935 de 2015 (requerimiento de inconstitucionalidad).

\section{NORMAS JURÍDICAS CITADAS}

DECRETO CON FUERZA DE LEY N 1.333 DE 1971, del Ministerio de Justicia, que fija texto de la Constitución Política del Estado. Diario Oficial, 25 de octubre de 1971.

DECRETO SUPREMO N 100 DE 2005, del Ministerio Secretaría General de la Presidencia, que fija el texto refundido, coordinado y sistematizado de la Constitución Política de la República de Chile. Diario Oficial, 22 de septiembre de 2005.

DECRETO N 778 DE 1989, que promulga el Pacto Internacional de Derecho Civiles y Políticos adoptado por la Asamblea General de la Organización de las Naciones Unidas por resolución № 2.200, el 16 de diciembre de 1966 y suscrito por Chile en esa misma fecha. Diario Oficial, 29 de abril de 1989.

DECRETO N 873 DE 1991, del Ministerio de Relaciones Exteriores, que aprueba la Convención Americana de Derechos Humanos, denominada "Pacto San José de Costa Rica". Diario Oficial, 5 de enero de 1991.

LEY N $\mathrm{N}^{\circ} 19.638$, que establece normas sobre la constitución jurídica de las iglesias y organizaciones religiosas. Diario Oficial, 14 de octubre de 1999.

LEY № 20.609, que establece medidas contra la discriminación. Diario Oficial, 24 de julio de 2012. 